\title{
THE CHALLENGES OF DISTANCE LEARNING DURING THE COVID-19 PANDEMIC: THE CONTEXT OF LITHUANIAN PRE-SCHOOL TEACHERS' OPINIONS
}

\author{
Ieva Bilbokaitė-Skiauterienè \\ Vilnius University Siauliai Academy, Lithuania \\ Renata Bilbokaitė \\ Vilnius University Siauliai Academy, Lithuania
}

\begin{abstract}
The COVID-19 pandemic has brought unprecedented challenges to the education system. Since Lithuania has declared the state-level emergency in February 2020, imposed by quarantine, the educational process was organized in a distance mode. Distance learning, namely, was a platform that pre-schools used to meet the learning needs of children.

The aim of this article is to review pre-school teachers' opinions about the challenges of distance learning during the Covid-19 pandemic. The article describes the situation in Lithuanian pre-schools using distance learning during the lockdown. The authors analyse the main problems that pedagogues have faced with - lack of competence in the use of IT, poor support from management, inadequate material base, lack of time and teachers' selfconfidence, the low involvement of families.
\end{abstract}

Keywords: challenges, distance learning, the covid-19 pandemic, pre-school teachers, Lithuania, content analysis, reflections.

\section{Introduction}

Today's education faces enormous challenges as the world struggles with the COVID-19 pandemic. The COVID-19 outbreak has severely disrupted education and training opportunities for learners and teachers across the European Union. Though distance education has been researched from many angles, however, this is particularly relevant in the context of a pandemic. According to Musingafi et al. (2015) „distance learning has grown into an important global strategy in resolving problems of access to education". Distance learning includes the use of assessments that promote academic self-regulation, the challenges involved in assessing online classes and collaboration with teachers / students (Moore \& Kearsley, 2011, Smaldino et al., 2008, Valentine, 2002, Kearns, 2012. 
Many researchers (Venčkauskas et al., 2021, Salieva, 2020, Musingafi et al., 2017, Golysheva et al., 2017, Damary et al., 2017, Kamau, 2007, Mossberger et al., 2003, Thorpe, 2002, Zirnkle, 2001, Garland, 1993) emphasize the challenges of distance learning from a student perspective - high chances of distraction, complicated technology, no social interaction, difficulty staying in contact with pedagogues, changing role of pedagogues, lack of academic writing skills, lack of material base, lack of time and technical competence.

Starting from spring 2020, distance learning is carried out in all educational institutions in Lithuania. The results of research conducted by Lithuanian researchers (Venčkauskas et al., 2021) revealed that "the situation of distance learning causes changes in the daily routine, which are extremely important in the lives of teachers, parents and children". This is illustrated by the study, which found that "the emotional state of more than a third of children deteriorated during quarantine, and children with better learning outcomes experienced more physical health problems". A top issue emerged when students spent much more time at screens. It is revealed that students' motivation to learn has decreased, which is related to the lack of social context, when students lose a direct, individual relationship with teachers and peers. However, distance learning during quarantine caused tension and stress not only for students and teachers, but also for parents who lacked guidance, assistance with planning daily activities, limiting time spent at computers, motivating children, and other challenges.

These negative aspects of distance learning are offset by the results of another study (The Impact of Distance Learning on Municipal Learning, 2020), which states that distance learning has helped students become more independent, able to plan and manage time, ask questions and ask for help. Cooperation between teachers and students was also strengthened, as the latter contributed to the development of the curriculum, were able to offer various learning methods and sources of information.

The goal of this study was to review pre-school teacher's opinions about the challenges of distance learning during the Covid-19 pandemic.

The problem of the research. In order to keep education running and to pursue educational goals, educational institutions had quickly adapt to the situation. To accommodate this, teachers had to face the challenges and organize the education process in a different way. This supposes the problem questions: How do pre-school pedagogues handle distance learning techniques and materials? Was the continuity of the pedagogical education process ensured by distance teaching and learning? What challenges of distance education have been encountered by participants of the survey? 


\section{Theoretical Basis of the Study}

Distance education consists of studying from home where students and teachers are physically distant. According to Sadeghi (2019), it is different from traditional education, because „electronic means are used to keep students in touch with teachers, provide access to communication between students and bridge the gap and distribute educational material though distance learning programs“. One of the most important challenges of distance learning for educators is to motivate students to learn independently and to promote responsibility for their own learning outcomes. So, determining autonomy of distance education has a critical importance (Firat, 2016, Jacobs et al., 2016, Lynch, Dembo, 2004).

Based on the analysis of the scientific literature, the advantages and disadvantages of distance learning have been identified (Figure 1). One of the advantages of distance learning is learning in a home environment where both educators and students can feel relaxed, motivated to acquire knowledge or pass it on. The cosiness of home does not oblige, it provides emotional and physical comfort, when it is possible to feel free, to model the teaching / learning process, adapting to the needs of oneself and family members. The potential for money saving is also emphasized (Bijeesh, 2017, Brown, 2017), where both children and teachers are not required to meet clothing or other requirements when learning in a home environment. Various measures for the educational process are also spared. The advantage is that learning / working remotely saves time (Bijeesh, 2017) for travel to / from the educational institution, as well as energy.

There are challenges in distance learning, such as high chances of distraction (Salieva, 2020). It is emphasized that learning or working remotely at home may not lead to timely activities due to changing motivation. Therefore, the distance learning process requires concentration and achievement of the set learning goals. Although distance learning/ teaching offers opportunities to save money on travel, clothing, educational materials, but at the same time it requires pedagogues and families to invest in information technology, various programs. One of the most significant disadvantages is the lack of social interaction (Dyrud, 2000; Hara \& Kling, 2000) when working outside the educational institution. This can affect the psychological well-being of students, teachers, and parents, cause problems of self-realization, isolation, and burnout. It can also limit successful communication between students and pedagogues. One of the most pressing challenges is the lack of material base, when teachers lack educational tools, computer equipment, and everything that would ensure high-quality transmission of educational content remotely. Damary et al. (2017) emphasizes the changing role of the teacher in the 
Bilbokaité-Skiauteriene \& Bilbokaite, 2021. The Challenges of Distance Learning During the Covid-19 Pandemic: the Context of Lithuanian Pre-School Teachers' Opinions

virtual classroom, where the focus is on the student, the relationship between the teacher and the student becomes equal.

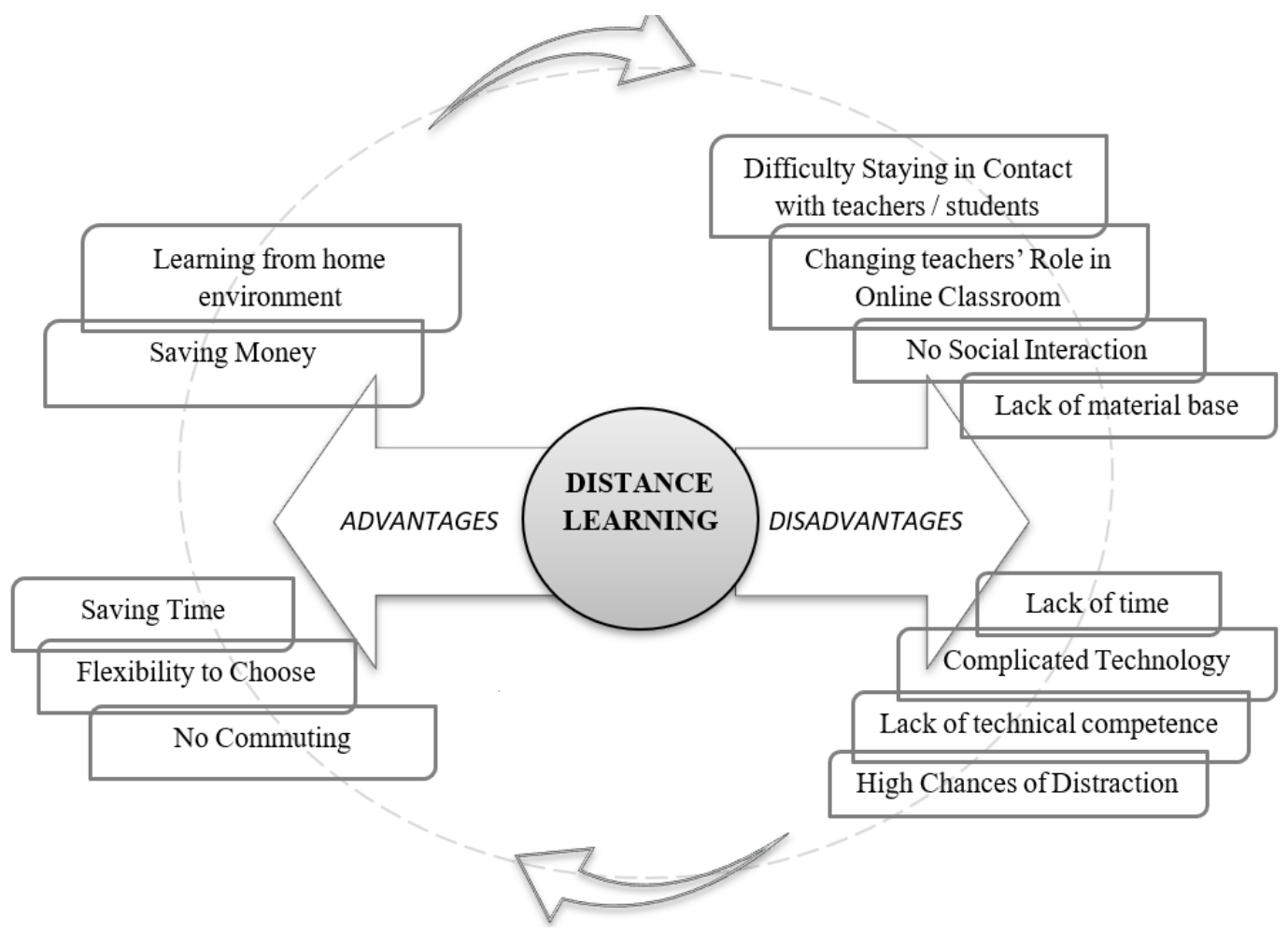

Figure 1 Advantages and Disadvantages of Distance Learning

(composed by the authors on the basis of Salieva, 2020, Musingafi et al., 2017, Golysheva et al., 2017, Bijeesh, 2017, Brown, 2017, etc.)

Having summarised the discussed advantages and disadvantages of distance learning, it can be stated that in the distance learning process it is necessary to focus on strengthening students' self-directed learning, focusing on setting learning goals, time planning, finding, and organizing necessary information, independent tasks, learning and capacity building for self-assessment of results.

\section{Research Methodology}

The article presents qualitative analysis of the reflections of pedagogues, employing the method of content analysis which enabled objective and systematic investigation of the features of the text, generalisation of information and formation of appropriate conclusions. 69 reflections of $\mathrm{X}$ Lithuanian kindergartens were analysed from September to November 2020. The content of the reflections was transcribed in separate protocols. The analysis has been conducted by consistently analysing the content of a text, dividing the content under investigation into analytical units, i.e. categories, sub-categories, which are 
particular aspects of pupils' perception of interculturality, expressed through the representing statements. The latter are coded (e.g. [1] etc.) according to the order of essays presented by the surveyed, aiming at anonymity of the research participants.

\section{Research Results}

The content of teachers' reflections on the challenges of distance learning reveals the essential categories and subcategories (Figure 2), illustrating the opinion of specialists in the context of the analysed problem. During the first quarantine, teachers most often faced the lack of material facilities, when "computers were not provided" in educational institutions [9], or "teachers lacked them" [24], and "there was no possibility to take a printer / scanner, laminator to their homes" [25], as a result of which teachers "had to work on their computers at home” [9, 13], “all IT equipment” [20]. In such a situation, the pedagogues took the initiative and "purchased a computer, a camera at their own expense" [36]. The distance learning process did not run smoothly because "not all educators were able to attend ZOOM meetings" [16] and "some students were unable to join activities because they did not have the means to do so" [6]. The problem of lack of methodological tools was also highlighted, noting that "there was a lack of textbooks, educational publications for work with pre-school children in the digital space” [20], "tools for various works at home” [26], "work materials" [27, 21]. , "methods" [28]. Teachers overcome this challenge "by working with the personal tools at their disposal" [27, 20], or by creating them themselves, "filming tasks, using the help of children and grandchildren" [13]. The participants of the study highlight the lack of clear guidelines in the absence of a "description of distance learning" [20], no uniform information on "what and how to do specifically, how to assess whether the work done is appropriate" was provided [26]. All this led to a lack of systemic work [20]. There is a lack of training when "no distance or platform training was organized" [58, 69]. However, management expected good results from educators [1]. Information on the organization of distance education was scattered, leading to a lack of " $a$ single platform for generating all the necessary information, tools, sharing experiences” [28].

The title of the category Lack of teachers' IT competence reveals its content, which testifies to the lack of knowledge about IT management, when teachers lacked "knowledge to work with platforms" [9, 40], which was the most difficult to master because "not all teachers knew how to use information or smart technologies" [7, 14], "smart technologies" [14], "could not work properly on a computer" [38]. Teachers "lacked some knowledge of how to work remotely" [11] and "computer skills" [34], technological competences [31]. Therefore, the study participants note that they could not use all the methods of distance 
teaching, when, due to the lack of experience of working with new digital programs, they "did not know how to organize a virtual quiz" [1], "look for information sources in virtual space that could contribute to the curriculum" [36]. It can be concluded that if an analogous situation were to recur, it would be difficult to work remotely, as there would be a "lack of computer literacy" [9]. The content of the sub-category Lack of ICT skills of elder teachers reveals a lack of ICT skills among elder educators [42], which has led them to "choose holidays rather than distance work during the quarantine period" [26]. This has affected the quality of the results of the work of the whole institution: not all barriers to distance learning have been overcome due to "many retirees who are unable to take advantage of IT innovations” [20].

Educators often noted that one of the challenges of distance learning was Poor support from management. This category is based on the transfer of responsibility, noting that the management recommends that educators "agree with the parents themselves on the acceptable ways of educating their children" [57], decide on "methods to involve and motivate children in the educational process" [15]. This testifies to the fact that educators made decisions about the educational process, its content, and solved the problems with the help of colleagues. Lack of support / respect is highlighted, when in such complex situations, which educators had to adapt to very quickly, there was a lack of simple support, help, understanding and, above all, respect from managers, authorities [25, 27, 63, 33], because "there were quite a lot of worries" [35]. It is revealed that "the administration has done nothing to help the elderly teachers" [42], which suggests that in the already mentioned situation, when the latter lack ICT competences, they do not receive the necessary help from managers, as a result of which the educators did not work and their work load was not redistributed to other colleagues. Such situation causes tension between colleagues, complicates their daily activities. The lack of information is also emphasized, when leaders did not provide precise instructions, did not inform "what to do" [27]. The content of the sub-category High Obligations highlights another difficult situation, when "management required teachers to persuade parents to engage in distance learning and for children to be more active" [15]. 


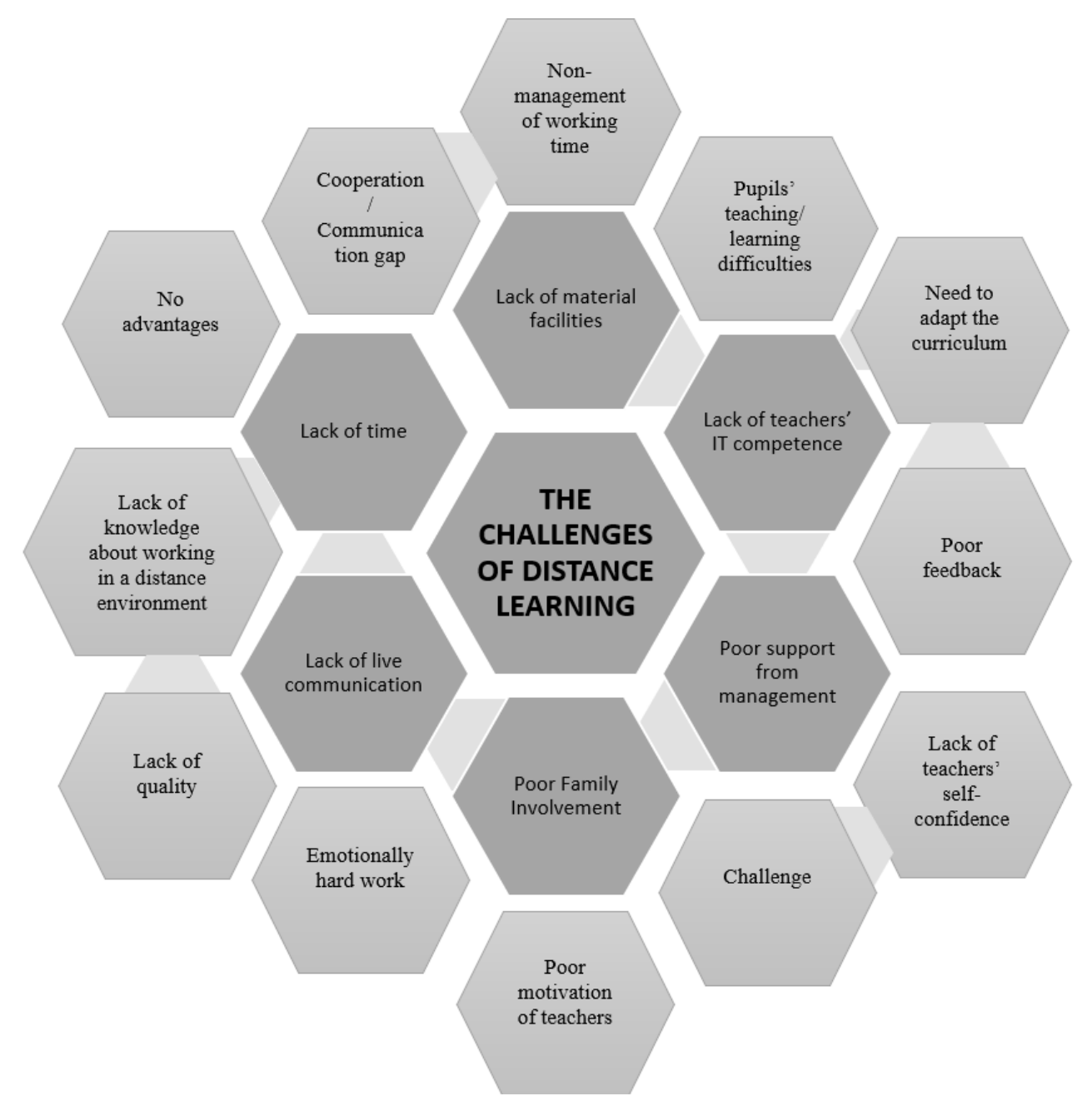

Figure 2 Schematization of the Challenges of Distance Learning (composed by the authors)

The content of the category Poor Family Involvement reveals the reasons for the non-participation of parents and children in distance learning. The subcategory Parents' attention to school-age children highlights the passive involvement in distance activities in families where school-age children grow up together with pre-schoolers. Parents could not distribute their time and attention equally to all children, so priority and "full attention was paid to the education of school-age children" [7], when with the younger ones "they were able to watch videos at best and did little work with" [66]. Parental involvement was also aggravated by the lack of time, when the latter could not "actively engage, participate in activities, provide feedback through children's works, photos" $[2,3]$. This situation was due to the fact that the parents worked remotely at home and took care of the children at the same time, thus "being burdened with their own work and the homework of their children" [8]. Pedagogues singled out the lack of cooperation when "some parents lacked cooperation, understanding, and 
respect” [40, 22]. Some families were poorly involved in the distance learning process, as the importance of education was underestimated when "parents did not attach much importance to pre-school education" [7]. Reluctance to participate in distance education also became apparent when "more than a half of parents refused to participate in distance education. Many of them asked for the tasks to be uploaded and they would do them when they had time, together with the children" [57]. Reasons why it was more difficult for parents with children to engage in distance education were parental lack of IT competence ("very poor knowledge of computer-virtual application management of parents" [17]) and the lack of IT tools, when teachers found it difficult to "ensure education process with parents, children, because not everyone had computers" [16], "there was no internet connection and computers for every child in some homes" [62].

One of the most frequently highlighted categories is the lack of live communication, its content reveals a lack of interaction with children. It is noted that "no one will replace live, natural communication, contact with the child" $[4,12]$, direct work [21], "live" education [41]. At the time of distance education, teachers lack interaction with children the most [13], as there is no "feedback that is expected" [21], and teachers miss children [32]. However, it is not only teachers who lack live communication, which is supported by the opinion: "after a month of distance work, children lacked live communication with teachers. They used to say that they wanted to show us the work they did live, not through the camera" [30]. The lack of connection is emphasized, when "there is a lack of children's emotions, connection with the students, because they work virtually, communicating "through the screen" [21]. The participants of the research revealed the benefits of Communication for the educational process - "better explanation of information, more attention focusing" [10], more open communication, less fatigue $[62,17]$.

The most emphasized category is the lack of time, the name of which presupposes the allocation of time resources by teachers to prepare for distance education. It is noted that during the quarantine, teachers had limited time to prepare for activities. They "lacked the time to transfer tasks into the digital space" [20], "to implement and prepare for activities" [22, 40], as they had to prepare all the materials for distance learning within a week [2]. It is noted that "the content of the videos, with morning activities, was modelled by the teachers themselves, they collected and developed tools, methods, etc. They themselves looked for ways to reveal the material through video (not live) so that children could understand it as much as possible" [2]. As the time to prepare for the activities was limited, the teachers were not provided with the necessary tools and created them themselves, they used what they had [20], "worked as they understood and knew" [27]. The complexity of reconciling time for family and work is highlighted, when working remotely at home made it difficult for teachers 
to "do the household chores and at the same time be able to upload tasks for children, communicate with them, evaluate the tasks completed" [52]. It also reveals a change in routine, when during the quarantine "there was a lack of normal routine, leaving home, usual activities" [21].

The category Pupils' teaching/ learning difficulties reveals difficulties faced by both children and pedagogues. It is stated that pupils felt a lack of competition, which was noticed by the teachers from the material recorded during the activities. The participants of the study note that "children lacked competition, which deprived them of half the fun of their tasks" [3]. The content of the subcategory Non-completion of tasks highlighted that some families had difficulties in completing tasks, "there were families who did nothing" [7, 3] and some children "did not complete all tasks" [48]. This was due to pupils' lack of motivation, when "children are less motivated and it is harder for them to concentrate when they are at home. The parents were worried about that" [4]. Educators encountered the complexity of assessing children's achievement, "it was obvious that parents contributed to the work" [4]. The reduced attention of teachers to the child is actualized, which manifests itself in more frequent direct communication with parents [21], when tasks and daily activities were coordinated.

One of the challenges of distance education is the lack of knowledge about working in a distance environment, when teachers lack experience [13], knowledge, understanding, information and skills [19, 12, 26, 29], how to start working remotely [39], how to communicate with parents, children, what to do in case of problems [19]. In this situation, teachers worked with the tools they had and knew how to work best with [12].

The content of the categories Poor feedback reveals difficulties in communicating with children and parents. The research data emphasize poor parental involvement, when teachers' relationship with parents was weaker during distance learning, because less feedback was received [2], not all parents communicated $[4,11]$. It is concluded that poor parental involvement weakened the effectiveness of distance learning ("I did not like distant education with my children because there was no feedback from my parents, so I didn't always get pictures of children's works, I didn't know how they were doing” [32]). Poor feedback from children is also actualized, when there was no quality communication with children [22] and there was a huge lack of it [28], because it is important for pedagogues to communicate with children, know how they felt in the home environment or participated in activities and completed tasks.

Distance learning is described by pedagogues as emotionally hard work, tedious [20], leading to "professional burnout" because quarantine was understood as vacation and leisure time at home, although it required a great deal of time and effort [29]. Working in cyberspace was different from working in 
Bilbokaité-Skiauteriene \& Bilbokaite, 2021. The Challenges of Distance Learning During the Covid-19 Pandemic: the Context of Lithuanian Pre-School Teachers' Opinions

kindergarten, when it was noted that "we had live chats in Zoom, but there was a bit of chaos because the work was done with young children who wanted to play on a computer and had difficulty to concentrate because of extraneous sounds in the background" [30]. One of opinions when assessing the differences between remote and direct work with children becomes clear - "it was more difficult to work than directly, because from the morning, when you upload the day's topics to Facebook, until the evening, you are tensed, constantly working and following each activity review, waiting for children photographs of the works completed" [15]. However, distance learning has been challenging not only for pedagogues but also for parents. It is stated that "parents who worked with children at home remotely realized that it was really difficult and required a lot of time, attention, concentration, and patience" [41]. Distance work during quarantine is described as a Challenge. For teachers, this was a new experience when "working in this situation was a challenge because it had not been tried anywhere" [7]. It is emphasized that the educational institution and educators were able to adapt to the challenge and organize education in a different way [30]. However, the view has emerged that not all pedagogues are prepared for distance learning [8]. It is noted that these were Sudden changes, "teachers were provided with too much and too abrupt information that they had to process in a very short time" [22]. Uncertainty about the nature of the work [26], implementation of activities, communication difficulties were also felt.

The meaningful content of the category Cooperation / Communication gap revealed the gaps in communication with parents, colleagues, administration [7]. It is regrettable that "teachers were left alone to deal with this situation [15], there was a lack of information on how to work, there was a lack of cooperation, there was a lack of consensus [23] - there was confusion among all teachers [18]. Statements in the category Non-management of working time reveal that "working hours remotely have no limits because there were parents who used to send works at night" [4]. An example of full-time pre-quarantine workload "was tripled at the time of quarantine, lacked time" [20] due to constant day-to-day communication with parents and children [32]. Emphasis is placed on the need to adapt the curriculum, when educators had to adjust their artistic activities and assignments while working remotely, taking into account the parents' ability to perform tasks [3]. Pedagogues had to get out of the situation, think about how to prepare and adapt, and pass on the tasks to the students and their parents [16]. The lack of teachers' self-confidence became apparent when they noted they lacked belief in oneself $[39,26]$ and the ability to adapt to a difficult situation. The emphasis is also placed on Poor motivation of teachers to take an interest in themselves and to do something [29] and the lack of quality, when distance learning was completely of poor quality, as pedagogues focused more on themselves than on students [22]. The participants of the study also highlight the 
position when there are no advantages, only disadvantages in distance education [20], because it is stated that "children already learn to use computers and digital technologies by themselves" [10].

\section{Conclusions}

The results of the study reveal that during the pandemic, the problem of lack of competence in the use of IT by pedagogues (especially the elderly) became more pronounced after the introduction of distance education. Educators lacked support from management, adequate material base, training, and time to prepare for activities. One of the most obvious challenges is poor involvement of families in the distance learning process. Distance learning eliminated the possibility of direct, "live" communication with children, complicated the processes of motivating students and assessing achievement. The lack of teachers' selfconfidence and low motivation to participate in the distance learning process actively became apparent. For many teachers this was an absolutely new experience, creating uncertainty, tension and changes for which the latter were not prepared.

\section{References}

Bijeesh, N. A. (2017). Advantages and disadvantages of distance learning. Retrieved from https://www.indiaeducation.net/online-education/articles/advantages-anddisadvantages-of-distancelearning.html

Brown, C. (2017). Advantages and disadvantages of distance learning. Retrieved from https://www.eztalks.com/elearning/advantages-and-disadvantages-of-distancelearning.html

Damary, R., Markova, T., \& Pryadilina, N. (2017). Key Challenges of On-Line Education in Multi-Cultural Context. Procedia - Social and Behavioral Sciences, 237, 83-89.

Dyrud, M. A. (2000). The third wave: a position paper. Business Communication Quarterly, 63(3), 81-93.

Firat, M. (2016). Measuring the e-learning autonomy of distance education students. Open Praxis, 8(3), 191-201.

Garland, M. (1993). Ethnography penetrates the "I didn’t have time” rationale to elucidate higher order reason for distance education withdrawal. Research in distance education, 8(2), 181-198.

Golysheva, M. D., Didenko, A.V., Vlasov, M.V., \& Asadullina, L. I. (2017). Key Challenges of On-line Education in Multi-cultural Context. Procedia - Social and Behavioral Sciences, 237, 83-89. 
Bilbokaité-Skiauteriene \& Bilbokaitè, 2021. The Challenges of Distance Learning During the

Covid-19 Pandemic: the Context of Lithuanian Pre-School Teachers' Opinions

Golysheva, M. D., Didenko, A. V., \& Vlasov, M. V. (2011). Asadullina L.I. E-learning and distance education in Russia and abroad: problems and solutions. Retrieved from www.gramota.net/materials/2/2011/4/12.html

Hara, N., \& Kling, R. (2000). Student distress in a web-based distance education course. Information, Communication \& Society, 3(4), 557-579.

Jacobs, G. M., Renandya, W. A., \& Power, M. (2016). Learner autonomy. G. Jacobs, W. A. Renandya and M. Power (eds.), Simple, powerful strategies for student centered learning. New York: Springer International Publishing.

Kamau, J. (2007). Retraining primary school teachers against diminishing resources: Is distance education the answer? Conference paper, UNESCO, second regional seminar for Africa, Accra Ghana; UNESCO.

Kearns, L. R. (2012). Student Assessment in Online Learning: Challenges and Effective Practices. MERLOT Journal of Online Learning and Teaching, 8(3), 198-208.

Lynch, R., \& Dembo, M. (2004). The relationship between self-regulation and online learning in a blended learning context. The International Review of Research in Open and Distributed Learning, 5(2), 76-82.

Moore, M. G., \& Kearsley, G. (2011). Distance education: A systems view of online learning. Cengage Learning.

Mossberger, K., Tolbert, C. \& Stansbury, M. (2003). Virtual inequality: Beyond the digital divide. Washington, D. C.: Georgetown University Press.

Musingafi, M. C. C., Mapuranga, B., Chiwanza, K., \& Zebron, S. (2015). Challenges for Open and Distance learning (ODL) Students: Experiences from Students of the Zimbabwe Open University. Journal of Education and Practice, 6(8), 59-66.

Musingafi, M. C., Mapuranga, B., Chiwanza, K., \& Zebron, S. (2015). Challenges for open and distance learning (ODL) students: Experiences from students of the Zimbabwe Open University. Journal of Education and Practice, 6(18), 59-66.

Musingafi, M. C., Mapuranga, B., Chiwanza, K., \& Zebron, S. (2015). Challenges for open and distance learning (ODL) students: Experiences from students of the Zimbabwe Open University. Journal of Education and Practice, 6(18), 59-66.

Nuotolinio mokymo(si) ịtaka savivaldžiam mokymuisi. (2020). Tyrimo ataskaita. Retrieved from http://spt.moletai.lt/dokumentai/Tyrimo\%20apibendrinimas.pdf

Sadeghi, M. (2019). A Shift from Classroom to Distance Learning: Advantages and Limitations. International Journal of Research in English Education, 4(1), 80-88.

Salieva, Z. (2020). The Challenges Of Distance Learning In The Period Of Pandemic (The Case Of Teaching Speaking). International Journal of Advanced Science and Technology, 29(7), 2112-2116.

Smaldino, S., Albright, M., \& Zvacek, S. (2008). Teaching and learning at a distance. M. Simonson (Ed.). Upper Saddle River, NJ: Merrill.

Thorpe, M. (2002). Rethinking learner support: The challenge of collaborative online learning. Open learning, 17(2), 105-119.

Valentine, D. (2002). Distance learning: Promises, problems, and possibilities. Journal of Distance Learning Administration, 5(3), 67-89.

Venčkauskas, A. (2021). Distance Education of Children During the Covid-19 Pandemic: Threats and Opportunities From An Ecosystem Perspective. Project report. Retrieved from https://www.mediavaikai.lt/confinement-about-the-project

Zirnkle, C. (2001). Access barriers in distance education. Contemporary education, 72(2), 3942. 